\section{Regards sur l'économie allemande}

Bulletin économique du CIRAC

$67 \mid 2004$

Varia

\title{
Lobbying et communication
}

KÖHLER Tanja, SCHAFFRANIETZ Adrian (eds), Public Relations -

Perspektiven und Potenziale im 21. Jahrhundert / LEIF Thomas, SPETH

Rudolf (eds), Die stille Macht. Lobbyismus in Deutschland / NEUBERT

Kurt, SCHERER Helmut (eds), Die Zukunft der Kommunikationsberufe.

Ausbildung, Berufsfelder, Arbeitsweisen / RAUPP Juliana, KLEWES

Joachim (eds), Quo vadis Public Relations?

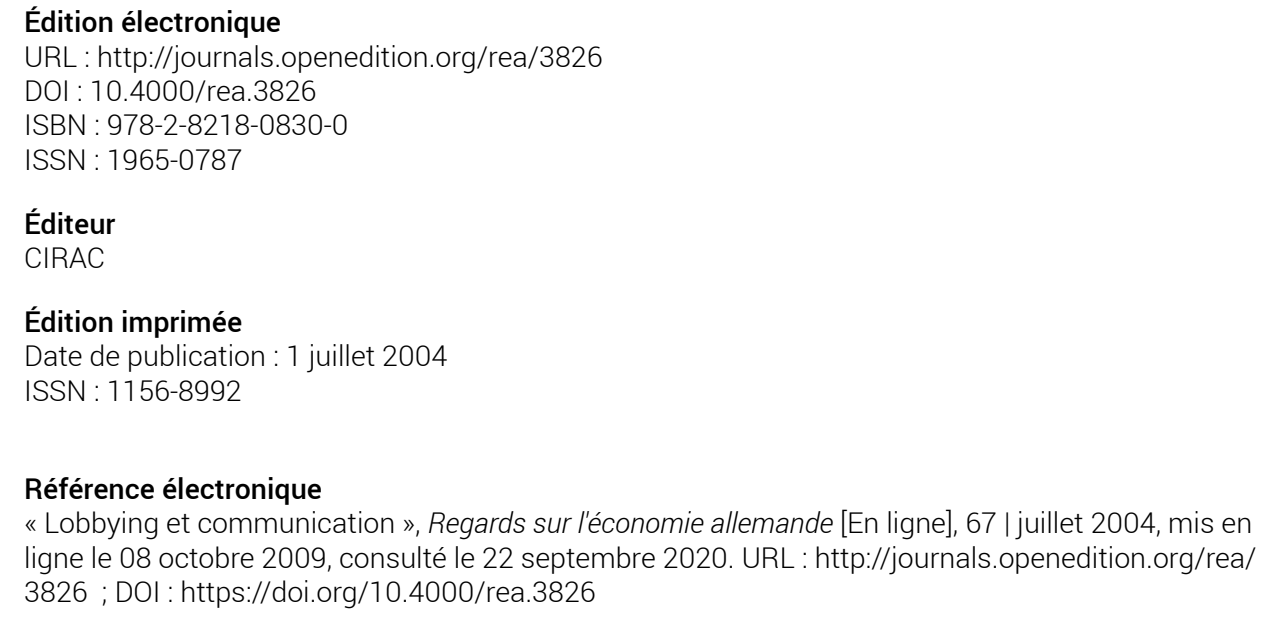

Édition imprimée

Date de publication : 1 juillet 2004

ISSN : 1156-8992

Référence électronique

"Lobbying et communication », Regards sur l'économie allemande [En ligne], 67 | juillet 2004, mis en ligne le 08 octobre 2009, consulté le 22 septembre 2020. URL : http://journals.openedition.org/rea/ 3826 ; DOI : https://doi.org/10.4000/rea.3826

Ce document a été généré automatiquement le 22 septembre 2020

(c) CIRAC 


\section{Lobbying et communication}

KÖHLER Tanja, SCHAFFRANIETZ Adrian (eds), Public Relations -

Perspektiven und Potenziale im 21. Jahrhundert / LEIF Thomas, SPETH

Rudolf (eds), Die stille Macht. Lobbyismus in Deutschland / NEUBERT

Kurt, SCHERER Helmut (eds), Die Zukunft der Kommunikationsberufe.

Ausbildung, Berufsfelder, Arbeitsweisen / RAUPP Juliana, KLEWES

Joachim (eds), Quo vadis Public Relations?

\section{RÉFÉRENCE}

KÖHLER Tanja, SCHAFFRANIETZ Adrian (eds), Public Relations - Perspektiven und

Potenziale im 21. Jahrhundert, VS Verlag für Sozialwissenschaften, Wiesbaden, 2004, $248 \mathrm{p}$.

LEIF Thomas, SPETH Rudolf (eds), Die stille Macht. Lobbyismus in Deutschland, Westdeutscher Verlag, Wiesbaden, 2003, 386 p.

NEUBERT Kurt, SCHERER Helmut (eds), Die Zukunft der Kommunikationsberufe.

Ausbildung, Berufsfelder, Arbeitsweisen, Schriftenreihe der DGPUK, vol. 31, UVK

Verlagsgesellschaft, Constance, 2004, 306 p.

RAUPP Juliana, KLEWES Joachim (eds), Quo vadis Public Relations?, VS Verlag für Sozialwissenschaften, Wiesbaden, 2004, 296 p.

1 En Allemagne, fédérations professionnelles, partenaires sociaux, s'expriment légitimement à la fois dans l'intérêt général (leurs membres contribuent à l'action collective) et pour faire valoir leurs intérêts particuliers. Mais le lobbying est en crise (voir REA 61/03), la défense de l'intérêt général marquant le pas. Un ouvrage collectif (LEIF et al.) retrace les évolutions d'une activité et de ses dérives. Ces dernières contribuent à jeter le discrédit sur un segment essentiel de la communication: les relations publiques, à la limite entre information 'pure' (informer l'opinion via la presse) et information 'intéressée' (manipuler l'opinion). Les métiers de la communication, apparentés à ceux du journalisme, ont considérablement changé, évoluant vers ce qu'il est convenu d'appeler le «management de la communication » (RAUPP et al.) avec ses techniques de gestion de crise, par exemple, ou 
d'internationalisation des stratégies (KOHLER et al.). Les formations à ces métiers de relations publiques se sont modifiées en conséquence (NEUBERT et al.) et se distinguent aujourd'hui de plus en plus du journalisme. (IB) 